\title{
Las enfermedades infecciosas en el Primer Congreso Médico Chileno
}

\author{
WALTER LEDERMANN D.
}

\section{Infectious diseases in the First Chilean National Medical Congress}

Entre el 15 y el 22 de septiembre de 1889 se realizó en la Universidad de Chile el Primer Congreso Médico Chileno con "un éxito que sobrepasó indudablemente las esperanzas de los organizadores. El número de adherentes fue casi inesperado y las comunicaciones leídas numerosas e interesantes", según se comenta en la Advertencia que encabeza el Tomo I de Actas y Trabajos, aparecido recién cuatro años después, en 1893 (con las típicas excusas de los editores chilenos por la tardanza).

La Comisión Directiva, designada por decreto supremo del Ministerio de Justicia e Instrucción Pública (22-6-1888), firmado por el Ministro Federico Puga Borne y por el Presidente Balmaceda, designaba como presidente del evento al Dr. José Joaquín Aguirre, a la sazón Rector de la Universidad y profesor de Anatomía Descriptiva. Integraban la Comisión Directiva, aparte del Ministro mismo, el Decano de la Facultad de Medicina, Dr. Manuel Barros Borgoño, y los distinguidos maestros Adolfo Valderrama, Isaac Ugarte, Máximo Cienfuegos, Vicente Izquierdo, Roberto Del Río, Federico Philippi, Alcibíades Vicencio y Octavio Maira. El objetivo fundamental de este Congreso era solemnizar la inauguración de la nueva Escuela de Medicina. El Supremo Gobierno destinó fondos especiales para los mejores trabajos en las distintas áreas, destacando uno de \$2.000 en el tema Proyecto de reforma de la farmacopea chilena y crítica racionalizada de la actual, con otros menores, de $\$ 500$ a $\$ 1.000$, en los temas Saneamiento de Santiago, Aguas termales de Chile, Estudio químico y terapéutico de plantas medicinales del país, Antisepsis y Tema libre.

El Congreso se dividió en 4 secciones: Medicina Interna, Cirugía, Higiene, Ciencias Físicas y Naturales. Podían participar en él los médicos titulados en la U. de Chile, los naturalistas y los químicos y farmacéuticos. Inscribiéndose con anticipación, cualquiera podía leer su trabajo in extenso en la sección correspondiente, siempre que no estuviese publicado. Si obtenía la aprobación de dos tercios del auditorio, podía presentarse luego a las Sesiones Generales, decidiendo la Mesa Directiva si merecía publicarse en el Libro del Congreso. Cada orador tenía 15 minutos, pero el que abría la sesión disponía de 20, tiempos que parecen imposibles cuando se tiene ocasión de leer los extensos discursos de la época. Se inscribieron 128 médicos de la capital y 114 de provincia, más 56 farmacéuticos y sólo 7 naturalistas (entre éstos, Rodulfo y Federico Philippi y Federico Johow). Solitaria representante del sexo femenino la doctora Eloísa Díaz.

"El domingo 15 de septiembre a las 2 P.M. (tomen nota, los organizadores modernos) tuvo lugar la sesión solemne de apertura en el salón central de la Universidad, que había sido arreglado especialmente para este fin. Los congresales, que no bajarian de trescientos, llenaban completamente el local...Las galerías estaban ocupadas por un gran número de estudiantes de medicina y algunas personas estrañas a la profesión. S.E. el Presidente de la República llegó acompañado de los seis ministros de estado..."

Pero omitamos los floridos discursos del ministro Puga y del Rector Aguirre y vayamos al tema que nos ocupa: ¿qué papel le cupo a la Infectología en este Congreso?. Desde luego que esta especialidad no existía formalmente, pero sabemos que SIEMPRE las enfermedades infecciosas han constituido la flor y esencia de la medicina. Prueba de ello es que, de los 18 trabajos discutidos en la sección Medicina Interna, diez versaban sobre enfermedades infecciosas:

1. De la fiebre recurrente, Dr. Juan Henríquez, Concepción.

2. De las inyecciones intramusculares de oleum cinereum en el tratamiento de la sífilis, Dr. Ramón Corvalán.

3. De la pneumonía fibrinosa, su naturaleza y tratamiento, Dr. Ugarte Gutiérrez.

4. Epidemia de fiebre dengue en Iquique, Dr. Luis Astaburuaga

5. De las variaciones de la temperatura en las distintas modalidades del cólera, Dr. Luis Espejo.

6. Tratamiento de los abscesos del hígado con yodoformo, Dr. Eleodoro Bourgeois, San Felipe.

7. Tratamiento del cólera, Dr. Eduardo Solovera.

8. Sobre antisepsia interna, Dr. Conrado Ríos.

9. Sobre la verruga peruana, Dr. Vicente Izquierdo.

10 Sobre equinococcus en Chile, Dr. Alejandro Del Río.

Resulta fascinante leer en las actas como el Dr. Roberto Del Río aportilla sus fiebres recurrentes al Dr. Henríquez, preguntándole si no serían "formas anómalas" de fiebre tifoidea, ya que no se practicó hemocultivos, o cómo el Dr. Polhammer le recuerda al Dr. Corvalán "que la literatura médica registra varios casos de muerte repentina" al inyectar su oleum cinereum a los luéticos, en tanto que el Dr. 
Deformes, de Valparaíso, acota que son tan dolorosas como los otros mercuriales que pretende reemplazar. Mejor le va al Dr. Ugarte con su neumonía fibrinosa, al afirmar que "ya no habrá duda para aceptar la naturaleza infecciosa de la enfermedad, como lo han demostrado en forma categórica los trabajos de Klebs, Friedländer y Fraenkel", afirmación que corroboran Puelma Tupper y Roberto Del Río.

Sin duda los trabajos que aparecen como más interesantes son los referentes al cólera y, especialmente, al dengue. Su lectura, sin embargo, resulta un tanto decepcionante, al faltar la microbiología. ¿Existió dengue en Iquique? "A principios de año apareció en Iquique una fiebre eruptiva que atacó indistintamente a los niños y a los adultos, siendo contados en el mes de julio los que habían escapado de contraer la enfermedad". Se la denominó el garrotazo. El autor, de paso en Iquique, tiene ocasión de examinar UN enfermo y, "a los once días cabales" enferma él mismo y puede observar y describir la enfermedad. Aún hoy en día, el diagnóstico de dengue se hace por los signos clínicos, más la situación epidemiológica. Si bien los signos sufridos en carne propia por el Dr. Astaburuaga son muy sugerentes de la forma clásica del dengue, falta la condición epidemiológica, es decir, falta el mosquito del género Aedes. ¿Qué dice el autor al respecto? No relata haber sido picado ni habla de mosquitos, aunque tiene noción de lo favorable del ambiente:

"La situación geográfica de Iquique, dentro de la zona tropical y a orillas del mar, la estación ardiente del año en que apareció la epidemia; la humedad de la atmósfera, producida por las camanchacas o neblinas; el defectuoso método, por falta de desagües, que se emplea para hacer el aseo de la población, etc, son condiciones todas para favorecer en el más alto grado la explosión de una epidemia de dengue". Se refiere luego al carácter de la epidemia, a su ausencia de mortalidad y a dos brotes ocurridos en la costa peruana, todo lo cual hace verosímil la posibilidad del dengue. A mayor abundamiento, dice que no fue alfombrilla, de la cual hubo numerosos casos en Iquique, cuyo exantema es distinto, existiendo, por lo demás, niños que hicieron primero el sarampión y luego esta nueva enfermedad. Ilustre pionero de la
Infectología, el Dr. Astaburuaga termina con un llamado a las autoridades para mejorar las condiciones sanitarias, a fin de impedir la importación de esa fiebre en el puerto.

En cuanto al cólera, el trabajo del Dr. Solovera que aparece en el programa oficial es reemplazado, sin explicación alguna, por uno del Dr. Benjamín Manterola: Tratamiento del cólera asiático por la enteroclisis, que había sido su reciente tesis para optar al grado de Licenciado en Medicina. Basándose en Koch y en el napolitano Catani, el joven investigador aplica la enteroclisis a los enfermos durante la segunda epidemia de cólera en Valparaíso, en diciembre de 1887. Como organizador y único médico del Lazareto de San Agustín, el Dr. Manterola asistió a 305 coléricos en 42 días de trabajo, con una mortalidad del 46\%. A los 13 que presentaron la forma más grave, llamada entonces tifoidea coléri$c a$, les aplicó enemas con una fórmula que comprendía ácido tánico, sublimado corrosivo, ácido salicílico, sulfato de quinina e hiposulfito de soda. "De los cuales perdí 4", relata el autor, lo cual confirma el Dr. Solovera, de Santiago: "He practicado 13 veces esta operación y sólo he tenido la desgracia de anotar tres defunciones". A esto sigue una movida discusión, pero baste, para terminar, el hermoso párrafo con que finaliza su exposición el doctor Manterola, demostrando que las dificultades para la investigación siguen siendo las mismas para quienes trabajamos en la medicina estatal:

"Reclamo de los señores congresales la más benévola indulgencia para apreciar las observaciones que presento, pues ellas no son más que las copias de los pocos casos, que en las papeletas de las propias camas de los enfermos pude apuntar. En el Lazareto San Agustín tenía yo que cumplir el deber de organizar el establecimiento y de atender a los coléricos y por esta falta de tiempo sólo los datos estadísticos son completos; siendo las relaciones clínicas simplemente rudimentarias".

\section{Bibliografía}

1.- Maira O. Primer Congreso Médico Chileno reunido en Santiago del 15 al 22 de Septiembre de 1880. Actas y trabajos. Tomo primero. Imprenta Nacional, Moneda 112, Santiago 1893. 